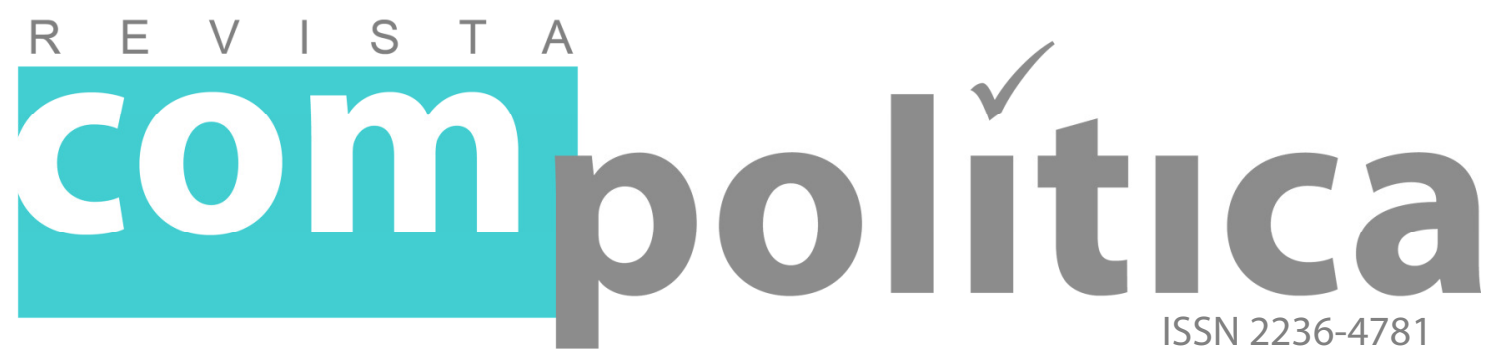

FERNANDES, Carla Montuori

Doutora e pós-doutora em Ciências Políticas pela PUC-SP. Mestre em Comunicação e Cultura das Mídias pela Universidade Paulista (UNIP). Professora da Universidade Paulista e do Centro Universitário Assunção. Pesquisadora do Núcleo de Estudos em Arte, Mídia e Política da PUC-SP.

<carla_montuori@ig.com.br>

\title{
Dilma Rousseff e a mídia internacional: uma análise do primeiro ano do mandato presidencial
}

\section{RESUMO}

A pesquisa "A liderança da presidente Dilma Rousseff na mídia internacional: uma análise dos jornais Le Monde, El Pais e New York Times" tem como objetivo estudar a cobertura do primeiro ano do novo mandato presidencial brasileiro que se iniciou em $1^{\circ}$ de janeiro de 2011, nos três principais sites de cobertura internacional, o espanhol El País, o norte-americano The New York Times e o francês Le Monde. Após oito anos no exercício do poder, Luiz Inácio Lula da Silva (PT) deixou a presidência do Brasil com elevado índice de popularidade nacional e imensa visibilidade internacional. Nesse sentido, pretende-se estudar qual será o destaque da sucessora Dilma Rousseff na mídia internacional e a tendência adotada pelos jornalistas ao retratar as diretrizes políticas nos sites de significativa credibilidade na Espanha, nos Estados Unidos e na França.

Palavras-chaves: Mídia internacional, Liderança, Dilma Rousseff.

\section{ABSTRACT}

The research "The leadership of President Rousseff in the international media: an analysis of newspaper Le Monde, El Pais and The New York Times" aims to study the coverage of the first year of the new presidency of Brazil that began on 1 January 2011 in the three main sites of international coverage, the Spanish El Pais, the U.S. the New York Times and the French Le Monde. After eight years in power, Luiz Inacio Lula da Silva (PT) of Brazil left the presidency with a high rate of huge national popularity and international visibility. Accordingly, we intend to study what will be the highlight of the successor Rousseff in the international media and the trend adopted by journalists to portray the new policy guidelines on the sites of significant credibility in Spain, the United States and France.

Keywords: International media, Leadership, Dilma Rousseff. 


\section{Dilma Rousseff e a mídia internacional: uma análise do primeiro ano do mandato presidencial}

\section{[Dilma Rousseff and international media: an analysis of the first year of the presidential term]}

FERNANDES, Carla Montuori

\section{Introdução}

$\mathrm{O}$ mandato presidencial no Brasil, que teve início em $1^{\circledR}$ de janeiro de 2011, marcou uma nova fase da política brasileira na mídia internacional. o presidente Luiz Inácio Lula da Silva (PT) deixou o cargo após oito anos de governo e indicou como sucessora a recém-eleita presidente Dilma Rousseff (PT), a única capaz de dar continuidade às metas e aos planos de governo deixados pelo ex-presidente.

A campanha de Dilma Rousseff contou com o forte apoio e a presença marcante de Lula (PT) no Horário Eleitoral Gratuito ${ }^{1}$, nas propagandas e nos comícios. As peças publicitárias da campanha procuravam estabelecer o máximo de sintonia entre Lula e Dilma, causando em alguns momentos a impressão de que não havia diferença entre ambos. Já o adversário direto da presidente Dilma Rousseff (PT) na campanha, o candidato José Serra (PSDB), do partido de oposição ao governo petista, questionava essa suposta sintonia e fomentava as dúvidas em relação ao futuro do país, ao insinuar que a candidata de Lula romperia com a política vigente do antecessor.

\footnotetext{
${ }^{1}$ O Horário Eleitoral Gratuito é um espaço reservado pela Lei № 4.737, que confere aos candidatos que concorrem ao pleito eleitoral o direito de exibição dos seus projetos de governos durante o período de campanha, simultaneamente na grade de programação de todas as emissoras de televisão aberta do país.
} 
A polarização da campanha ultrapassou a dimensão da opinião pública e da disputa partidária e ganhou espaço nas páginas da mídia internacional, com reportagens que ressaltavam a rivalidade entre os adversários, apontavam tendências futuras e declaravam sutilmente algum favoritismo. Além disso, existia nas matérias publicadas pelo jornalismo internacional uma desconfiança em relação à candidata Dilma (PT) e ao continuísmo da era promissora iniciada por Lula no cenário mundial.

Era o que aparecia em matérias veiculadas pelo correspondente internacional da Espanha no Brasil, Juan Arias, no site Elpaís.com, como a publicada com o título "O que virá depois de Lula?", que enaltecia a trajetória presidencial de Lula durante seus oito anos de mandato, com destaque para a posição que o país passou a ocupar entre as maiores potências emergentes do mundo, ao lado da China e da Índia. $\mathrm{Na}$ contramão, Arias questionava a candidata indicada por Lula, a petista Dilma Rousseff e associava sua imagem à da ex-guerrilheira e extremista de esquerda. A candidata do Partido dos Trabalhadores recebeu do correspondente Juan Arias severas críticas, ao enfatizar que ela: "É quase um anti-Lula, porque mais que uma improvisadora como ele, é uma gestora, que carece do carisma de seu chefe, que nunca disputou anteriormente eleições, nem para prefeita, e que chegou tarde ao Partido dos Trabalhadores"

Na mesma vertente, a reportagem do site do jornal The New York Times, publicada em 03 de outubro de 2010, trazia como tema a relação marcante entre Lula e Dilma ao pontuar que: "Especialistas não têm dúvida de que Rousseff irá prevalecer no segundo turno contra Serra" ${ }^{4}$. A matéria mencionava ainda a presença constante e o apoio de Lula na campanha de Dilma, ao apontar que com $80 \%$ de aprovação, depois de oito anos no governo, o carismático ex-líder está em toda parte, virtualmente garantindo a vitória de sua sucessora escolhida a dedo. A reportagem não

\footnotetext{
${ }^{2}$ Después de Lula ¿qué? Disponível em: <http://www.elpais.com/articulo/opinion/Despues/Lula/elpepuopi/20100215elpe piopi_12/Tes>. Acesso em: 26 de jan. 2011.

3 "Es casi un anti-Lula, porque más que una iluminada y una improvisadora como él, es una gestora, que carece del carisma desbordador de su jefe, que nunca se había presentado anteriormente a unas elecciones, ni para alcalde, y que llegó tarde al Partido de los Trabajadores".

4 "Analysts expressed little doubt that Ms. Rousseff, 62, would prevail in a second round against Mr. Serra".
} 
deixou de questionar a falta de experiência política e carisma da candidata a presidente Rousseff.

O jornal francês Le Monde tratou de maneira semelhante a candidatura da presidente petista, ao destacar na reportagem do dia $1^{\circ}$ de novembro de 2010 que, impulsionada pela alta popularidade de Lula, Dilma Roussef foi eleita presidente do Brasil no segundo turno da campanha, com 56\% dos votos contra $44 \%$ do seu adversário, o social democrata José Serra ${ }^{6} .0$ texto jornalístico ressaltou que Dilma teve como principal trunfo de campanha o balanço econômico dos anos do governo Lula, cujo crescimento espetacular permitiu que mais de $10 \%$ da população saísse da linha de pobreza. Como complemento, o jornal francês ressaltava a falta de carisma da sucessora e enaltecia a política de Lula durante os dois mandatos presidenciais.

As reportagens veiculadas nos principais sites de notícias internacionais, a saber: El País, The New York Times e Le Monde funcionavam como indicativo dos obstáculos que a nova presidente enfrentaria para conquistar a simpatia da mídia internacional, assim como os desafios para impor um estilo de liderança que permitisse visibilidade à Dilma Rousseff, desassociando sua imagem da figura bem-sucedida do antecessor. A pesquisa realizada pela Agência Imagem Corporativa sobre o retrato que os principais jornais do mundo expõem do Brasil mostrou que, no terceiro trimestre de 2009, 85\% das 783 matérias do Caderno de Economia e Política trazia uma imagem positiva e colocava o país como um player internacional. $^{7}$

Diante de toda a visibilidade midiática de Lula (PT) no cenário exterior, fazse importante questionar: Como foi a cobertura do primeiro ano de

\footnotetext{
5 "Despite her lack of political experience and public charm, she has ridden a wave of prosperity and good feeling in Brazil under the leadership of Mr. da Silva, whose approval ratings hover near 80 percent". Disponível em: <http://www.nytimes.com/2010/10/04/world/americas/04brazil.html?_r=0>. Acesso em: 26 de jan. 2011.

6"Propulsée par la popularité record de Lula, Dilma Rousseff a été élue au second tour de la présidentielle avec $56 \%$ des voix contre $44 \%$ à son rival socialdémocrate José Serra". Disponível em:

$<\mathrm{http} / / /$ www.lemonde.fr/ameriques/article/2010/10/31/bresil-dilma-rousseffdonnee-gagnante-a-la-presidentielle_1433679_3222.html\#ens_id=1395239>. Acesso em: 21 jan. 2011.

${ }^{7}$ A pesquisa foi feita em 14 dos principais jornais do mundo, como The Washington Post, Le Monde e China Daily. Disponível em:

<http://fdenoticias.wordpress.com/2009/11/03/pesquisa-mostra-que-lula-estacerto-imagem-do-brasil-no-exterior-e-positiva/>. Acesso em: 8 jun. 2010.
} 
mandato da presidente Dilma Rousseff na imprensa internacional, sobretudo nos sites de maior visibilidade mundial? Que imagem de liderança foi associada à presidente Dilma Rousseff nos sites dos jornais $E l$ Pais, The New York Times e Le Monde?

\section{Hipóteses, justificativas e metodologia}

A hipótese que conduzirá a pesquisa está baseada na veiculação midiática que conduziu todo o período de campanha eleitoral, relacionado à suposta falta de habilidade da presidente Dilma Rousseff para atuar no ambiente político brasileiro, marcado pelos fisiologismos e corporativismos.

A justificativa de estudar a imagem e a liderança do governo de Dilma Rousseff, a partir dos sites El País, The New York Times e Le Monde está relacionada à busca constante do ex-presidente Lula (PT), principalmente durante seu segundo mandato, para construir uma imagem positiva do Brasil no exterior. Segundo aponta Jorge (2010), ${ }^{8}$ no exterior o Brasil passa uma imagem de desenvolvimento e pujança que, ao se misturar com a figura de um presidente líder e estadista, contribuía para o enfrentamento das situações mais adversas no cenário internacional e a ampliação das políticas de negociações com os parceiros comerciais ao redor do mundo. A relevância deste estudo se complementa ao pontuar que os sites que servirão como objeto de análise estão entre os 14 jornais on-line mais influentes do mundo.

No jornalismo internacional, há duas maneiras de veicular as notícias: por meio do jornalismo de correspondência, mantido pelas principais agências de notícias do mundo, que comercializam matérias para as mídias nacionais e locais, e da cobertura de reportagens realizada por um enviado especial ao exterior. Com a disseminação da informação e a nova dinâmica global, as agências de notícias ou mesmo os grandes jornais possuem uma rede de correspondentes nas maiores cidades do mundo.

O diário El País, fundado em 1976, com sede em Madrid, conta com Juan Arias, correspondente e escritor que reside na cidade do Rio de Janeiro, e

${ }^{8}$ Política de comunicação garante sucesso do Brasil no exterior. Disponível em:

<http://www.midiaepolitica.unb.br>. Acesso em: 23 jan. 2011. 
envia diariamente reportagens sobre o cenário político brasileiro ao site jornalístico espanhol. O jornal The New York Times, com 60 anos de história, considerado uma referência mundial para conteúdos impressos e on-line, conta com o correspondente Alexei Barrionuevo, que também reside na cidade do Rio de Janeiro e é responsável por encaminhar ao site do jornal americano reportagens dos cinco países do cone do sul: Brasil, Argentina, Chile, Uruguai e Paraguai. Por fim, o francês Le Monde, considerado o jornal de maior prestígio internacional, fundado em 1944, conta com o jornalista e doutor em relações internacionais Nicolas Bourcier como correspondente internacional no Brasil.

A metodologia utilizada será a análise de conteúdo, da pesquisadora Bardin (2000), que estabelece três fases definidas para a análise de conteúdos jornalísticos, conforme segue: pré-análise, exploração do material e interpretação dos resultados. A fase de pré-análise refere-se à organização do material propriamente dito e compreende a formulação das hipóteses e dos indicadores que fundamentam a interpretação final. Os indicadores das reportagens serão definidos segundo a evocação do nome de Dilma Rousseff no conteúdo jornalístico e as menções ao seu estilo de gestão, considerando os itens de maior repetição.

Para interpretação das notícias veiculadas durante o primeiro ano de mandato de Dilma Rousseff, de janeiro a dezembro de 2011, foram desenvolvidas cinco categorias, a saber: "As marcas do passado de Dilma Rousseff", "O estilo de liderança de Dilma Rousseff", "A ruptura com a política do antecessor Luiz Inácio Lula da Silva", "A batalha contra a corrupção no governo de Dilma Rousseff" e "Dilma Rousseff e o campo político". Para contribuir com a análise interpretativa das matérias jornalísticas, será utilizado o conceito de valência, com o objetivo de identificar o enquadramento atribuído ao novo presidente e à sua gestão.

Desenvolvido pelo Laboratório de Pesquisa em Comunicação e Opinião Pública - Doxa - do Iuperj (Instituto Universitário de Pesquisas do Rio de Janeiro), o conceito de valência é uma metodologia que tem por finalidade verificar o enfoque dado às reportagens jornalísticas, buscando esclarecer se elas prejudicam ou beneficiam a imagem de um candidato, governo, ações e estratégias governamentais. A visibilidade de cada ator político 
aparece em uma metodologia que atribui valência positiva às matérias que reproduzem as promessas dos candidatos e governantes, às declarações ou ataques aos adversários e aos textos que destacam resultados favoráveis sobre suas metas e programas de governo. A valência negativa indica reportagens que reproduzem críticas às ações governamentais e aos ataques da oposição ou de terceiros ao governo. Já a valência neutra relaciona-se às matérias que apenas relatam ou citam a atuação do governo, sem expressar qualquer avaliação moral, política ou pessoal.

\section{Dilma Rousseff e a mídia internacional: uma análise dos jornais El País, Le Monde e New York Times}

A vitória de Dilma Rousseff nas eleições presidenciais de 2010 representou a supremacia do discurso da continuidade, mas foi cercada de enorme repercussão na mídia nacional e internacional. o fato de Dilma ser a primeira mulher da história política brasileira a assumir a presidência da República, de nunca ter ocupado um cargo público por eleição direta e ter um estilo de liderança totalmente divergente de seu antecessor e padrinho político, o ex-presidente Luiz Inácio Lula da Silva, suscitou na mídia inúmeras especulações sobre o sucesso político da escolhida de Lula.

O reconhecimento e o crescimento do Brasil como grande potência, a imagem positiva de Luiz Inácio Lula da Silva no exterior, com inúmeros prêmios e referências de grandes líderes políticos, faziam com que a imprensa internacional questionasse a suposta "falta de traquejo" da nova presidente, a quem eram atribuídos os títulos de "guerrilheira", "sisuda", "sem carisma", "sombra de Lula" e "rigorosa".

Nos primeiros meses de governo, a imagem da nova presidente ainda estava vinculada às informações do seu passado e à força política de seu antecessor Luiz Inácio Lula da Silva. As principais definições da presidente Dilma Rousseff vinham acompanhadas dos termos: Ex-guerrilheira; Sombra de Lula; Revolucionária; Ativista de extrema esquerda; Presa política; Grupo guerrilheiro da atual presidente brasileira. O quadro de valência refletiu um total de 13 reportagens que abordaram o passado de Dilma Rousseff, com cinco menções positivas e oito negativas. 
Quadro 1 - 0 passado de Dilma Rousseff

\begin{tabular}{|c|c|c|}
\hline Data & Jornais / Reportagens & Valência \\
\hline 01 de jan. & Le Monde - Brasil: Rousseff faz o juramento & Negativa \\
\hline 04 de jan. & $\begin{array}{l}\text { Le Monde - Itália fica indignada pela recusa do } \\
\text { Brasil de extraditar Battisti }\end{array}$ & Negativa \\
\hline 29 de out. & $\begin{array}{l}\text { Le Monde - Brasil cria uma Comissão da Verdade } \\
\text { para investigar a ditadura }\end{array}$ & Positiva \\
\hline 05 de jan. & $\begin{array}{l}\text { El País - Rousseff pede firmeza ao general e } \\
\text { ministro da segurança nacional no Brasil }\end{array}$ & Positiva \\
\hline 08 de jan. & El País - Tendências eleitorais na América Latina & Negativa \\
\hline 22 de jan. & $\begin{array}{l}\text { El País - O parlamento europeu encurrala Dilma e } \\
\text { Lula }\end{array}$ & Negativa \\
\hline 30 de jan. & $\begin{array}{l}\text { El País - O governo de Dilma Rousseff investigará } \\
\text { as torturas no cárcere }\end{array}$ & Positiva \\
\hline 31 de jan. & $\begin{array}{l}\text { El País - Rousseff viaja para a Argentina em sua } \\
\text { primeira visita como presidente do Brasil }\end{array}$ & Negativa \\
\hline 09 de mar. & $\begin{array}{l}\text { El País - O exército no Brasil se opõe à formação } \\
\text { de uma comissão de inquérito }\end{array}$ & Negativa \\
\hline 14 de abr. & $\begin{array}{l}\text { El País - Brasil pretende acabar com o "sigilo } \\
\text { eterno" dos documentos reservados }\end{array}$ & Positiva \\
\hline 15 de abr. & $\begin{array}{l}\text { El País - Documentos sigilosos secretos indicam } \\
\text { que o grupo guerrilheiro de Rousseff planejava } \\
\text { assassinar os oficiais do exército }\end{array}$ & Negativa \\
\hline 17 de abr. & $\begin{array}{l}\text { El País - O exército do Brasil ocultou documentos } \\
\text { sigilosos que comprometiam Cardoso e Lula }\end{array}$ & Negativa \\
\hline 04 de dez. & El País - A guerrilheira Rousseff & Positiva \\
\hline
\end{tabular}

É possível perceber uma concentração de reportagens com valência negativa no site do jornal espanhol El País, durante os meses de janeiro e abril. Ao retomar o passado de Dilma Rousseff, as reportagens evocavam termos pejorativos para retratá-la. 
As referências ao passado da presidente brasileira estiveram em pauta nas reportagens veiculadas, sobretudo durante o primeiro semestre do governo.

Concomitantemente, a mídia internacional ressaltava a personalidade e o estilo próprio de governar de Dilma Rousseff, já que a nova presidente surpreendia a mídia internacional e os líderes políticos com um estilo de governar extremamente diferente de Luiz Inácio Lula da Silva. A denominação de ex-guerrilheira, que marcou as reportagens veiculadas no mês de janeiro, foi substituída pelo perfil de austeridade e firmeza da nova presidente. A seguir, os termos que marcaram o estilo de liderança da presidente Rousseff: Mão de ferro; Tecnocrata e burocrática; Pragmática; Eficaz e ágil; Exigente e sóbria; Ética e transparente; Governo com "personalidade própria"; Super presidente; Líder competente.

O quadro de valência já indicava uma mudança de cenário, com um total de 14 reportagens positivas, que enalteciam a liderança de Dilma Rousseff, 4 neutras e apenas 3 matérias negativas.

Quadro 2 - Estilo de liderança de Dilma Rousseff

\begin{tabular}{lll}
\hline Data & Reportagem & Valência \\
03 de jan. & El País - As diferenças entre Lula e Dilma & Negativa \\
18 de jan. & $\begin{array}{l}\text { El País - Brasil prepara um plano detalhado para } \\
\text { prevenção de desastres }\end{array}$ & Positiva \\
19 de jan. & El País - Dilma impõe seu estilo ao Brasil & Positiva \\
28 de jan. & $\begin{array}{l}\text { El País - Brasil reconstruirá as casas após as } \\
\text { fortes chuvas }\end{array}$ & Positiva \\
11 de fev. & $\begin{array}{l}\text { El País - Em apenas 40 dias os sindicatos } \\
\text { ameaçam romper com Dilma }\end{array}$ & Positiva \\
16 de fev. & $\begin{array}{l}\text { El País - Rousseff enfrenta sua primeira batalha } \\
\text { política no Congresso }\end{array}$ & Positiva \\
17 de fev. & $\begin{array}{l}\text { El País - Dilma ganha sua primeira grande } \\
\text { batalha política no Congresso, contra a oposição } \\
\text { e os sindicatos }\end{array}$ & Positiva
\end{tabular}


16 de out. El País - Super Presidente Dilma: ela manda

Positiva

12 de jan. Le Monde - No Brasil as chuvas já mataram mais Neutra de 400 pessoas

15 de jan. Le Monde - Fortes chuvas no Brasil: a maior Neutra tragédia na história do país

16 de jan. Le Monde - Brasil: três dias de luto oficial após as Neutra chuvas torrenciais

21 de jan. Le Monde - O número de mortos pela inundação Neutra no Brasil pode ser maior que 1.000

23 de jan. Le Monde - Já soma mais de 800 o número oficial Positiva de mortes pela chuva no Brasil

12 de mai. Le Monde - Copa de 2014 e jogos olímpicos de 2016: o Brasil tem olhos maiores do que o estômago

16 de nov. Le Monde - Chevron está tentando conter um vazamento de óleo na costa do Rio

Positiva

Positiva multas pelo derramamento de óleo no Rio

Negativa saída dos seus ministros

Positiva

Positiva riscos naturais no Brasil

11 de out. New York Times - A liderança já não é um clube Positiva masculino

15 de nov. New York Times - Construindo um caminho para Positiva as mulheres no Brasil

Os primeiros passos de distanciamento da nova presidente Dilma Rousseff em relação à política internacional do ex-presidente Lula (PT) também despertaram a atenção da mídia internacional. A comparação com o governo Lula (PT) recebia um discreto destaque, porém o distanciamento e as medidas da nova presidente relacionadas à política externa estiveram nas pautas de inúmeras reportagens. As principais frases que definiram essa ruptura foram: Dilma Rousseff se distancia de Lula; Dilma Rousseff se afasta do seu tutor; O discurso de Dilma foi um claro indicativo de mudança 
na política exterior; Saiu da sombra do seu sucessor; Impôs um estilo próprio e diferente de governar; Um novo Brasil; Dilma já não é mais Lula; Mais sensível à problemática de corrupção que o antecessor Lula.

As mudanças na conduta da presidente Dilma Rousseff repercutiram de maneira positiva na imprensa internacional, com um total de 13 reportagens com valência positiva, enquanto apenas cinco obtiveram valência negativa e três neutras.

Quadro 3 - Ruptura com a política do antecessor Lula

\begin{tabular}{|c|c|c|}
\hline$\overline{\text { Data }}$ & Jornais / Reportagens & Valência \\
\hline 29 de jan. & $\begin{array}{l}\text { El País - Rousseff rompe os laços do Brasil com o } \\
\text { regime do Irã }\end{array}$ & Positiva \\
\hline 31 de jan. & El País - Brasil e Estados Unidos se aproximam & Positiva \\
\hline 10 de fev. & El País - Dilma Rousseff se distancia de Lula & Positiva \\
\hline 19 de mar. & $\begin{array}{l}\text { El País - As discordâncias obscurecem os acordos } \\
\text { no encontro entre Obama e Dilma }\end{array}$ & Negativa \\
\hline 22 de mar. & $\begin{array}{l}\text { El País - O governo de Rousseff pede "um cessar } \\
\text { fogo efetivo" horas depois de Obama deixar o } \\
\text { país }\end{array}$ & Positiva \\
\hline 25 de mar. & El País - Em três meses, Rousseff já não é Lula & Positiva \\
\hline 16 de set. & El País - O que acontece com o governo de Dilma? & Positiva \\
\hline 26 de out. & $\begin{array}{l}\text { El País - O que acontece com os ministros do } \\
\text { Brasil? }\end{array}$ & Positiva \\
\hline 16 de dez. & $\begin{array}{l}\text { El País - Em consenso popular, Dilma supera Lula, } \\
\text { no primeiro ano do mandato }\end{array}$ & Positiva \\
\hline 08 de fev. & $\begin{array}{l}\text { Le Monde - Dilma Rousseff prefere o Boeing F-18 } \\
\text { ao Rafale }\end{array}$ & Negativa \\
\hline 08 de fev. & $\begin{array}{l}\text { Le Monde - O prefeito de São Bernardo testa o } \\
\text { Rafale, Gripen e F-18 }\end{array}$ & Negativa \\
\hline 09 de fev. & $\begin{array}{l}\text { Le Monde - Rumores de uma batalha em torno da } \\
\text { escolha do Rafale no Brasil }\end{array}$ & Negativa \\
\hline 09 de fev. & $\begin{array}{l}\text { Le Monde - Paris e Dassault ainda esperam } \\
\text { vender o Rafale para o Brasil }\end{array}$ & Negativa \\
\hline
\end{tabular}


24 de fev. Le Monde - Nenhuma decisão brasileira sobre o Neutra Rafale até final de 2011

09 de jul. Le Monde - Brasil não tomará uma decisão sobre Neutra o Rafale até 2012

18 de fev. New York Times - Obama visitará a América Positiva Latina em março

17 de mar. New York Times - Na visita do Obama a líder do Positiva Brasil objetiva a reconciliação

18 de mar. New York Times - Obama encontra um novo Brasil Positiva

19 de mar. New York Times - Em tempos de crises, Obama Positiva visita América do Sul

26 de mar. New York Times - Interesse da China por terras Positiva produtivas deixa o Brasil incomodado

$\mathrm{O}$ alto desempenho de Rousseff esteve relacionado à intolerância com a corrupção e às medidas econômicas adotadas para que a economia brasileira continuasse em crescimento.

A suposta falta de tolerância do governo de Dilma Rousseff contra as acusações de corrupção dos seis ministros que foram afastados, durante o primeiro ano de mandato, ajudou a consolidar a imagem de uma líder séria, eficaz e, sobretudo, ética. Rousseff passou a ser retratada pelas reportagens dos jornais como a presidente capaz de solucionar os problemas que afligem o Brasil desde o seu descobrimento: a ilegalidade do sistema político. Seguem abaixo os principais termos evocados nas reportagens: Dilma quer limpar a casa; Presidente intolerante com a corrupção; Operação de limpeza; Rigor e ética na gestão do dinheiro público; Tolerância zero na batalha contra a corrupção; Alérgica a qualquer tipo de ilegalidade.

Apesar de as reportagens retratarem desacertos no sistema político brasileiro, a imagem de Dilma Rousseff saiu fortalecida, com 26 reportagens com valência positiva, 11 com valência negativa e cinco neutras. 
Quadro 4 - Corrupção no governo Dilma Rousseff

\begin{tabular}{|c|c|c|}
\hline Data & Jornais / Reportagens & Valência \\
\hline 21 de jan. & El País - Primeira baixa no governo de Dilma & Positiva \\
\hline 25 de mai. & $\begin{array}{l}\text { El País - Lula sai em defesa de Rousseff no } \\
\text { primeiro escândalo de sua gestão }\end{array}$ & Negativa \\
\hline 28 de mai. & $\begin{array}{l}\text { El País - A fiscalização brasileira investiga o } \\
\text { patrimônio do "número 2" do governo }\end{array}$ & Negativa \\
\hline 08 de jun. & El País - A maldição da Casa Civil & Negativa \\
\hline 08 de jun. & $\begin{array}{l}\text { El País - O homem forte do governo de Dilma se } \\
\text { demite por um escândalo de corrupção }\end{array}$ & Negativa \\
\hline 20 de jul. & $\begin{array}{l}\text { El País - A imprensa torna-se uma ativista contra } \\
\text { a corrupção no Brasil }\end{array}$ & Neutra \\
\hline 27 de jul. & $\begin{array}{l}\text { El País - O problema de corrupção nunca foi tão } \\
\text { grave como agora }\end{array}$ & Negativa \\
\hline 01 de ago. & $\begin{array}{l}\text { El País - A corrupção coloca Rousseff entre a } \\
\text { espada e a parede }\end{array}$ & Positiva \\
\hline 04 de ago. & $\begin{array}{l}\text { El País - Mal-estar da presidente do Brasil com } \\
\text { seu ministro de defesa }\end{array}$ & Positiva \\
\hline 05 de ago. & $\begin{array}{l}\text { El País - O ministro de defesa do Brasil, Nelson } \\
\text { Jobim, sai do governo arrastado por suas } \\
\text { declarações polêmicas }\end{array}$ & Positiva \\
\hline 08 de ago. & El País - Dilma Rousseff volta a ser Lula da Silva? & Negativa \\
\hline 09 de ago. & $\begin{array}{l}\text { El País - Detido o vice-ministro do turismo por } \\
\text { corrupção }\end{array}$ & Neutra \\
\hline 15 de ago. & $\begin{array}{l}\text { El País - O senado no Brasil soma esforços para } \\
\text { combater a corrupção }\end{array}$ & Positiva \\
\hline 18 de ago. & $\begin{array}{l}\text { El País - O machado de Dilma Rousseff toca no } \\
\text { osso }\end{array}$ & Positiva \\
\hline 20 de ago. & $\begin{array}{l}\text { El País - Os empresários do Brasil se unem a } \\
\text { Rousseff na batalha contra a corrupção política }\end{array}$ & Positiva \\
\hline 07 de set. & $\begin{array}{l}\text { El País - Começa no Brasil um movimento de } \\
\text { indignados contra a corrupção }\end{array}$ & Positiva \\
\hline 19 de set. & $\begin{array}{l}\text { El País - As praias de Copacabana estão cheias de } \\
\text { vassouras em protesto contra a corrupção }\end{array}$ & Positiva \\
\hline 29 de set. & El País - O machismo persegue Rousseff & Positiva \\
\hline
\end{tabular}


06 de out. El País - Dilma Rousseff quer limitar os "super Positiva salários" públicos

16 de out. El País - Brasil enfrenta um novo caso de

Positiva corrupção governamental

26 de out. El País - O ministro do Esporte do Brasil renuncia Positiva acusado de escândalo de corrupção

27 de out. El País - Os escândalos de corrupção afetam o Positiva governo brasileiro

29 de out. El País - Corrupção no Brasil Positiva

15 de nov. El País - O governo de Rousseff soma um novo Neutra escândalo de corrupção

21 de nov. El País - 62 juízes no Brasil suspeitos de lucrar Positiva com a venda de sentenças

05 de dez. El País - Rousseff perde o seu ministro do Positiva Trabalho acusado de corrupção

08 de jun. Le Monde - Dilma Rousseff perde seu principal Negativa ministro acusado de enriquecimento ilícito

09 de jun. Le Monde - O braço direito de Dilma Rousseff Negativa pediu demissão após um escândalo

10 de jun. Le Monde - Fim da paz no governo de Dilma Negativa

07 de jul. Le Monde - Brasil: Nova renúncia de ministro por Positiva corrupção

19 de ago. Le Monde - Demissão do ministro da Agricultura Positiva

20 de set. Le Monde - Os brasileiros se mobilizam contra a Positiva corrupção

21 de set. Le Monde - Os brasileiros querem varrer a Positiva corrupção

13 de out. Le Monde - Brasil tem seus indignados Positiva

19 de out. Le Monde - Ministro do Esporte no Brasil está sob Neutra investigação

28 de out. Le Monde - Demissão de um novo ministro Positiva acusado de corrupção

7 de jun. New York Times - Um importante membro da presidência brasileira saiu do cargo após um Negativa escândalo 
8 de jun. New York Times - Ainda há dúvidas sobre o novo Negativa assessor da presidente no Brasil

9 de jul. New York Times - A queda do segundo ministro Positiva no Brasil mostra que a nova presidente está limpando a casa

04 de ago. New York Times - Brasil: cai ministro da Defesa Neutra

18 de ago. New York Times - Brasil: ministro da Agricultura é Positiva o quarto oficial a renunciar

26 de out. New York Times - Queda do ministro do Esporte Positiva no Brasil

A cada novo escândalo de corrupção, os jornais analisados retratavam a postura firme e ágil de Dilma Rousseff, negociando rapidamente a saída do ministro acusado. As reportagens que obtiveram valência negativa ocorreram, sobretudo, no início do mandato de Rousseff e envolveram o ex-ministro da Casa Civil, Antônio Palocci, que, durante o governo do expresidente Luiz Inácio Lula da Silva, também esteve envolvido em escândalos de corrupção e foi afastado do cargo. Os demais episódios serviram apenas para reforçar a imagem da liderança austera de Rousseff.

Os questionamentos da liderança de Dilma Rousseff durante o período de campanha e logo após a sua eleição desenvolvia-se em torno da governabilidade da primeira presidente mulher do Brasil. Apesar de contar com total apoio do ex-presidente Luiz Inácio Lula da Silva e manter firme a aliança com o PMDB, construindo uma forte base governista, a falta de traquejo de Rousseff era vista com o maior desafio para a política de coalizão, que exige maior capacidade de articulação política. Para descrever os passos da governabilidade da presidente brasileira Rousseff, durante o primeiro ano do mandato, as reportagens utilizaram os seguintes termos: Aproximação com a oposição (PSDB); Líder pragmática; Caráter forte e objetivo; Figura austera; Capacidade de driblar barreira; Posição firme e atuação rápida; Dificuldade para governar.

A atuação de Dilma Rousseff no campo político permitiu a construção de 13 reportagens com valência positiva e oito com valência negativa. 
Quadro 5 - As marcas da governabilidade de Dilma Rousseff

\begin{tabular}{|c|c|c|}
\hline Data & Jornais / Reportagens & Valência \\
\hline 03 de jan. & $\begin{array}{l}\text { El País - Rousseff arranca seu mandato com uma } \\
\text { equipe econômica continuísta }\end{array}$ & Positiva \\
\hline 03 de fev. & $\begin{array}{l}\text { El País - Governo tem maioria esmagadora no } \\
\text { Congresso }\end{array}$ & Positiva \\
\hline 03 de jan. & $\begin{array}{l}\text { El País - Rousseff planeja privatizar os novos } \\
\text { aeroportos no Brasil }\end{array}$ & Negativa \\
\hline 25 de mai. & $\begin{array}{l}\text { El País - O Congresso no Brasil aprova anistia } \\
\text { para os destruidores da floresta amazônica }\end{array}$ & Negativa \\
\hline 25 de mai. & $\begin{array}{l}\text { El País - Rousseff mobiliza o exército em função } \\
\text { do aumento de } 27 \% \text { da destruição da Amazônia }\end{array}$ & Negativa \\
\hline 08 de jun. & El País - Rousseff solta as amarras de Lula & Positiva \\
\hline 11 de jun. & $\begin{array}{l}\text { El País - Dilma aposta em um governo de } \\
\text { mulheres fortes e gestoras }\end{array}$ & Positiva \\
\hline 13 de jun. & $\begin{array}{l}\text { El País - Por carta, Rousseff elogia o trabalho de } \\
\text { Cardoso no Brasil }\end{array}$ & Positiva \\
\hline 28 de jun. & $\begin{array}{l}\text { El País - Dilma vence um tabu e inicia a } \\
\text { aproximação com os sociais-democratas no } \\
\text { Brasil }\end{array}$ & Positiva \\
\hline 06 de jul. & $\begin{array}{l}\text { El País - Dilma perde um segundo ministro por } \\
\text { corrupção }\end{array}$ & Positiva \\
\hline 07 de jul. & El País - Por que os brasileiros não reagem? & Positiva \\
\hline 13 de jul. & $\begin{array}{l}\text { El País - A presidente Rousseff anuncia a } \\
\text { concessão de } 7 \text { milhões de euros de crédito para } \\
\text { pequenos agricultores }\end{array}$ & Positiva \\
\hline 16 de jul. & El País - Por que os brasileiros gostam de Dilma? & Positiva \\
\hline 24 de ago. & El País - E agora, o que fará Lula? & Positiva \\
\hline 28 de ago. & $\begin{array}{l}\text { El País - A imprensa acusa Dirceu de conspirar } \\
\text { contra Rousseff }\end{array}$ & Negativa \\
\hline 31 de ago. & $\begin{array}{l}\text { El País - O principal líder da oposição brasileira } \\
\text { solicita um pacto de governabilidade com } \\
\text { Rousseff }\end{array}$ & Positiva \\
\hline 06 de set. & $\begin{array}{l}\text { El País - Dilma Rousseff retoma um projeto do PT } \\
\text { para controlar a mídia }\end{array}$ & Negativa \\
\hline
\end{tabular}


30 de nov.

El País - A presidente Dilma Rousseff prepara

Positiva para janeiro uma remodelação governamental

11 de nov. New York Times - Brasil: milhares de protestos cercam as receitas petrolíferas

Negativa

02 de dez. New York Times - Brasil rompe os muros de

Negativa silêncio

20 de dez.

$$
\begin{aligned}
& \text { New York Times - Fantasmas do regime militar } \\
& \text { começam a se mexer }
\end{aligned}
$$

Negativa

A reportagem do jornal El País, "Por que os brasileiros gostam de Dilma?" ressaltou traços do perfil político da presidente brasileira, que em apenas seis meses de mandato conquistou a simpatia de 45 milhões de brasileiros, com sua posição firme e atuação rápida diante dos casos de corrupção do governo. Com postura diferente do antecessor, o ex-presidente Lula (PT), que defendia os possíveis culpados, alegando que eram inocentes até que a justiça mostrasse o contrário, Dilma traçava um rumo diferente e afastava os suspeitos, até que provassem a completa isenção de culpa.

Por fim, na esfera política, os jornais analisados reconheceram a figura de Dilma Rousseff como grande líder, conferindo visibilidade aos discursos e projeções da presidente brasileira nos encontros mundiais. Desta forma, a presidente Dilma Rousseff saiu dos holofotes negativos da imprensa e terminou o primeiro ano do mandato com reconhecida liderança no cenário internacional.

\section{Considerações finais}

Ao assumir a presidência do Brasil, Dilma Rousseff possuía consideráveis desafios, entre os quais estava a consolidação de um estilo de liderança próprio, que desvinculasse sua imagem da do ex-presidente Lula, e a superação da discriminação midiática e dos estereótipos recorrentes nos meios de comunicação de massa ao retratarem a figura da mulher na política.

\footnotetext{
9 “Por qué Dilma gusta a los brasileños". Disponível em: <http://elpais.com>. Acesso em: 01 set. 2011.
} 
No primeiro ano de mandato, a presidente Dilma Rousseff iniciou um caminho de aparente ruptura com a conduta do ex-presidente Luiz Inácio Lula da Silva. o ponto mais crítico da gestão de Lula, a inércia diante dos escândalos de corrupção dos ministros e assessores, foi conduzido por Dilma Rousseff de forma intolerante e ágil. A presidente brasileira terminou o primeiro ano do governo com seis ministros afastados por suspeita de corrupção.

O possível engajamento de Dilma Rousseff para eliminar a corrupção no gabinete ministerial permitiu que a presidente, favorecida pelas representações midiáticas, construísse a imagem de líder racional, em constante luta para se livrar das amarras de políticos inescrupulosos. Até o estereótipo de gênero, associado à conduta rigorosa e rude da presidente, ajudou a compor a imagem de que é mais difícil corromper as mulheres do que os homens no governo de Rousseff.

Já no cenário internacional, Dilma Rousseff é considerada uma importante liderança, que soube conduzir o país com diplomacia. Com o apoio da propaganda oficial, ao impor seu modelo de gestão, Dilma Rousseff incorporou um estilo de liderança técnico, rigoroso e ético, capaz de atrair a atenção dos meios de comunicação, conquistando expressivos índices de popularidade. Para o público interno, a presidente Rousseff enfrenta os problemas do país e demite os ministros acusados. O prestígio de Rousseff também se repete no exterior, onde a visão do quadro político é simplista. Para grande parte da imprensa internacional, a presidente brasileira é tida como responsável por promover uma faxina no governo para acabar com a corrupção, ao demitir políticos do alto escalão.

O ex-presidente Lula se apoiou na imagem de líder carismático para garantir o prestígio no exterior. Já sua sucessora Dilma Rousseff está apoiada na imagem da líder burocrático-legal.

Entre suas realizações, Rousseff abriu caminho para o debate com a oposição, negociou com governadores de partidos oponentes e reconheceu os méritos do ex-presidente Fernando Henrique Cardoso, com quem mantém uma relação harmoniosa. No plano econômico, manteve a política desenvolvimentista do antecessor, o ex-presidente Lula, com forte controle inflacionário e rigorosa disciplina fiscal. Ao lado do ministro da Economia, 
Guido Mantega, que ocupa o cargo há seis anos, foi Dilma Rousseff quem colheu os resultados de um país avaliado como a sétima maior economia do mundo. Terminou o primeiro ano do seu mandato com $71 \%$ de aprovação popular, índices maiores que os conquistados pelos ex-presidentes Fernando Henrique Cardoso e Luiz Inácio Lula da Silva, durante o mesmo período.

Analisando os noticiários internacionais do jornal espanhol El País, do norte-americano New York Times e do francês Le Monde, foi possível perceber uma mitificação em torno da imagem da presidente brasileira, enquanto Dilma Rousseff consolidava os primeiros meses do mandato. 


\section{Referências}

AMORIM, Maria Salete Souza de. 0 reflexo da opinião pública nas eleições 2010 e as expectativas em relação ao Governo Dilma. In: IV Encontro da Compolítica, 2011, Universidade Estadual do Rio de Janeiro, RJ.

ADGHIRNI, Zélia Leal. Valores-notícia e credibilidade no jornalismo on-line. In: II Encontro Nacional de Pesquisadores em Jornalismo - SBPJOR, 2004, Salvador.

BARDIN, Laurence. Análise de conteúdo. Trad. Luís Antero Reto e Augusto Pinheiro. Lisboa: Edições 70, 2000.

CALDEIRA, Helder. A 1푸 Presidenta. Rio de Janeiro: Faces, 2011.

CHAIA, Vera. Jornalismo e política: escândalos e relações de poder na Câmara Municipal de São Paulo. São Paulo: Hackers, 2004.

GOMES, Wilson. Transformações da política na era da comunicação de massa. São Paulo: Paulus, 2004.

LIMA, Venício A. de. Mídia: teoria e política. São Paulo: Fundação Perseu Abramo, 2001.

WOLF, Mauro. Teorias da comunicação. 7. ed. Lisboa: Presença, 2002.

COMPOIITICA

ASSOCIACÄO BRASILEIRA

DE PESQUISADORES EM COMUNICACAOO E POLITICA

Presidente: Alessandra Aldé (UERJ)

Vice-Presidente: Luis Felipe Miguel (UnB)

Secretário Executivo: Francisco Jamil Marques (UFC)

Editora-Chefe:

Alessandra Aldé (UERJ)

Editores Executivos:

Edna Miola (UFS) e Viktor Chagas (UFF)

Editores Assistentes:

Eleonora Magalhães (UFF) e Fernanda Sanglard (UERJ)

Revisor: Pedro Sangirardi (UERJ)
A Revista Compolítica é uma revista eletrônica da Associação Brasileira de Pesquisadores em Comunicação e Política. Com periodicidade semestral, sua proposta é difundir a produção acadêmica relacionada às interfaces desses campos de estudo.

Ao citar este artigo, utilize a seguinte referência bibliográfica

FERNANDES, Carla Montuori. Dilma Rousseff e a mídia internacional: uma análise do primeiro ano do mandato presidencial. In: Revista Compolítica, n. 3, vol. 2, ed. julho-dezembro, ano 2013. Rio de Janeiro: Compolítica, 2013. 